\title{
MOOCS 2.0: THE SOCIAL ERA OF EDUCATION
}

\author{
Arda SOYLEV \\ Department of Computer Engineering \\ Necmettin Erbakan University \\ Konya, Turkey
}

\begin{abstract}
The improvements in the Internet technology led an evolution in education. Some students' lives have changed since 2012 when the MOOCs gained popularity among the academia. The students now take courses from the top universities all around the world without time limitations and they even earn credits for their courses. They are able to discuss lecture topics not only with their instructors in the class but also with thousands of other online students and can get just-in-time help regarding to their questions from teaching assistants. These are some of the practices from the new era of MOOCs called "social MOOCs" or MOOC 2.0. The concepts of collaboration, blended learning and TAs are the new consequences. In this paper, we review the problems and the current solutions associated with MOOC 1.0 era. In the light of these, we analyze the MOOC 2.0 era and discuss its present and possible future affects to our lives.
\end{abstract}

Keywords: MOOCs 2.0, online learning, blended learning, distance learning, MO0Cs, distance education.

\section{INTRODUCTION}

The world is becoming a place where the Internet is at the core of every activity. Education is one of the primary activities of the world. From a small kid to an old man, anyone wants to learn and this ambition lasts forever. Schools are the traditional medium for this, but can everyone go to a school in every part of their lives? An old man, a businessman, or even a student who wants to learn an additional topic may not be able to go to a traditional school. Massive Open Online Course, MOOC is a new concept, which has been popular since 2012, fills this gap. One of the most popular MOOC platforms, Coursera, around 15 million students, 1872 courses and 142 partner institutions across 28 countries. This number is nearly 200 times more than the largest University in US, based on the number of enrollments. Coursera is an academic platform where students can take courses and certificates from the top Universities around the world for free or with a small amount of fee. The education system is moving towards online and people are questioning whether there will be a need for big campuses in the future?

MOOCs are not the first to present online lectures. Previously, online lectures were only available in the form of camera recordings inside the real classrooms. The watchers were like one of the students inside the class who were not able to ask any questions but watch an old recording of the lecture and there was no interaction. In this context, MIT's OpenCourseWare was one of the best approaches. Being launched in 2002, MIT put all of its course materials online. Without a sign-up process, anyone was able to access a lecture's quizzes, exams, reading materials and some of the courses' lecture videos. As of March 2016, MIT has 2340 online courses and 88 of them has complete video recordings. 
The term MOOC originated in 2008 by Dave Cormier in response to a course called Connectivism and Connective Knowledge in University of Manitoba, Canada. It is the first online course, which had 25 fee-paying, and 2200 free online students (Parr, 2013). Shortly after, open online education platforms like Khan Academy, iTunesU and TED were also beginning to evolve. They offered tutorial like contents with short video formats that were supportive to classwork materials (Sandeen, 2013).

The MOOC act's popularity begins in 2012, which is regarded as "the year of MOOCs" (Pappano, 2012). Three MOOC providers, Coursera, edX and Udacity emerged that year, which are still the most popular ones. Two Stanford Computer Science Professors Andrew Ng and Daphne Koller lead Coursera and Sebastian Thrun, who was also from the Stanford Computer Science Department lead Udacity. On the other hand, edX was founded by MIT and Harvard Universities. To emphasize the impact of MOOCs, the Artificial Intelligence course given by the Stanford University online in 2012 had 58,000 people signed up from all around the world. This number is four times the aggregate student count of Stanford University (Markoff, 2011).

What differs the MOOC approach from the rest is that the online courses of MOOCs are made only for the online students. There are video recordings, assignments, exams, and even projects on a weekly schedule according to the topics of the course. The videos have shorter lengths than a typical 40 - 45 minute lecture. Based on studies like (Guo et al., 2014), to keep the student engagement at maximum, each week's video is chunked into roughly 10-minute segments based on the subject's subtopics, similar to Khan Academy, which is the first to endeavor this. Most importantly, students of a MOOC class are able to collaborate with each other through forums.

Today, MOOCs can be used all over the world by anyone in any age. A 15-year old Mongolian passing the Circuits and Electronics course in MIT is one of the many examples (Daniel, 2012). People now are wondering how it will change the classical education system. According to a recent study, in class and online students learn equally (Colvin et al., 2014). In 2 years, we saw a great change in MOOCs itself. Now the MOOCs are more interactive and they need to be so because without one-on-one interaction, the learning pedagogy cannot be fulfilled. This leads to integrating (TAs) Teaching Assistants into the MOOCs, which we discuss briefly inside the text.

The rest of the paper is organized as follows; In Section 2, we discuss the previous problems of MOOCs, which are completion rates, pedagogy and certification. We summarize the current solutions to these. In Section 3, we express the evolution of MOOCs where some of the authors suggest the name MOOC 1.0 and MOOC 2.0. We analyze the MOOC 2.0 era in the spirit of blended learning and teaching assistants. Finally, we state our opinions about the future of MOOCs and conclude our paper.

\section{PREVIOUS PROBLEMS AND CURRENT SOLUTIONS}

MOOCs are a revolution in the current education system, however it still has serious problems according to some researchers. We divide these problems into three categories as Completion Rates, Pedagogy and Certification vs. University Credit. Using the current approaches as our arguments, we endeavor to convince the readers that these problems are mostly solved.

\section{Completion Rates}

The quality of a higher education institution is measured by several factors where the completion rate is one of the most significant one. People tend to evaluate MOOC platforms according to the same criteria as a regular institution and come up with a completion rate of a 
single digit. Some critics say that this is one of the most significant failures of MOOCs, however, today, some people changed the way they look at these numbers.

According to a paper (Koller et al., 2013), 40,000 to 60,000 people enrolled in a typical MOOC given by Coursera in 2012. However, only 50 to 60 percent of these people returned for the first lecture, 15 to 20 percent of the people watching the lectures submitted an assignment for grading and among these, about $\mathbf{4 5}$ percent completed the course successfully and earned a statement of accomplishment. Therefore, the success of a student in a MOOC class cannot be evaluated with these numbers.

Participants of MOOCs are very diverse and have different intentions. Some of them want to learn the course deeply, some are only interested in a particular topic of the course and do not follow all the lectures, some are only curious, just looking once to the course's website and maybe some are high school students analyzing the lectures to decide his/her major at the University level. There may be many more reasons why people enroll to a course and not get a statement of completion. The participants of the MOOCs can be divided into five categories as given below and Fig.1. (Hill, 2013);

$>$ No Shows: Participants who register but not login when the course is active. Daphne Koller, one of the Coursera's founders says that this number decreases when the course announcement is closer to the start date.

$>$ Observers: They just login, browse content and read discussions.

$>$ Drop-Ins: These participants do some activity like watching lectures, but not complete the entire course

$>$ Passive Participants: They watch lectures, take quizzes and read discussions but they do not complete the assignments.

$>$ Active Participants: These are the students who fully participate to the lecture.

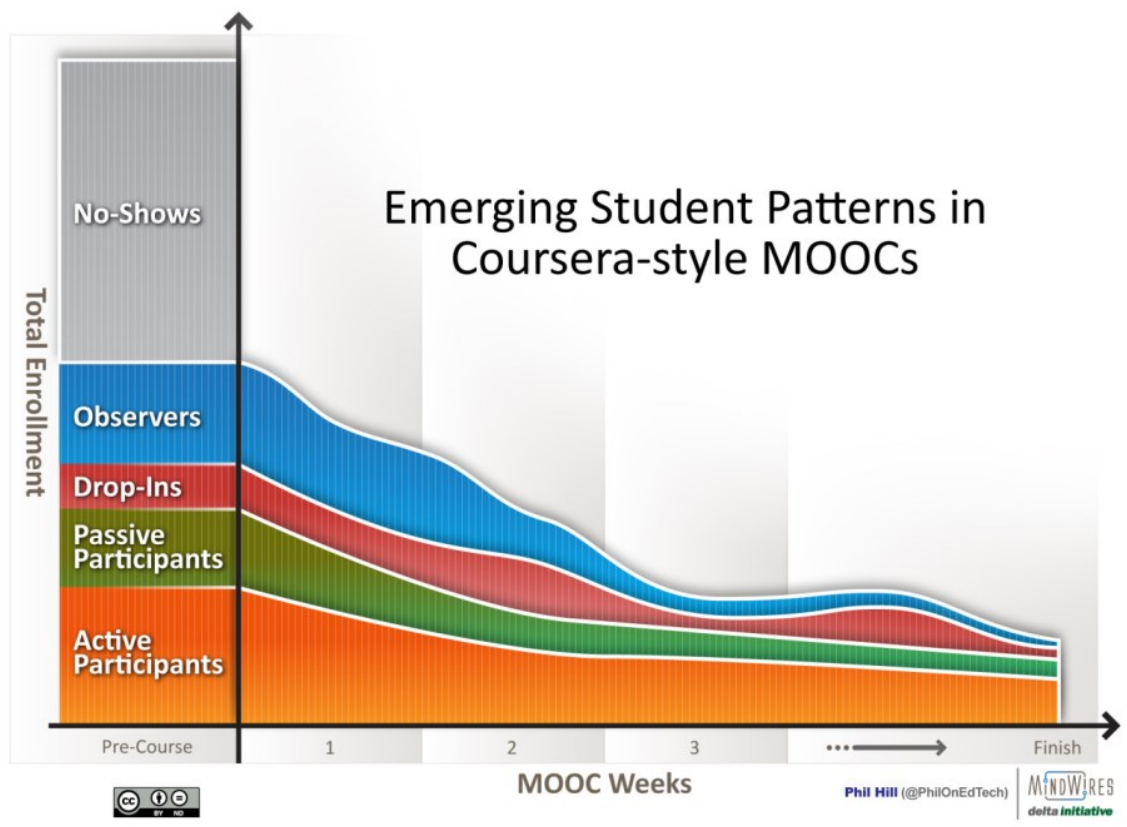

Figure 1. MOOC participant types (Hill, 2013) 
Therefore, the intent of the participating students is the most important input to decide if the course is successful or not. Fig.2., highlights a key point for this discussion.

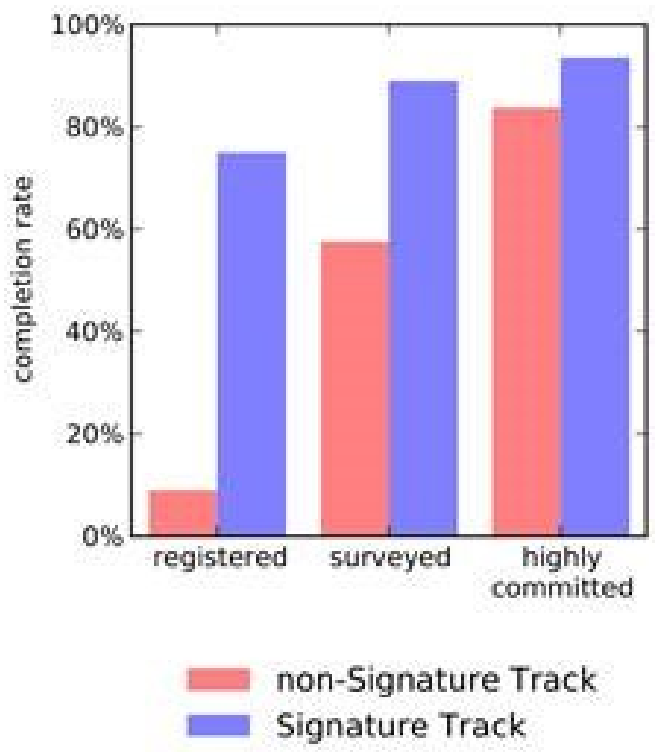

Figure 2. Completion rates of "Nutrition for Health Promotion and Disease Prevention" (Koller et al., 2013, fig. 4)

In the figure, a comparison between non-signature track and signature track students is made for the first signature-track class of Coursera, "Nutrition for Health Promotion and Disease Prevention". Signature track students pay a fee to get an official certificate in the completion of the same course by participating in keystroke biometric and photo based identity verification (Maas et al., 2014). Therefore, the aim of these students is truly to complete the course. The numbers show a 74 percent completion rate for these students whereas the rate for a regular registered student is only 9 percent. The surveyed students are the ones who indicate a strong intent to finish the course after the first month of the course's start date and highly committed students are the ones who indicated a high commitment to finishing the course by watching all the lectures and finishing all the assignments.

\section{Pedagogy}

MOOCs are regarded as the new era of learning and therefore, many claims whether it is pedagogically sound or not are being made (Daniel, 2012; Bates, 2012; Glance et al., 2013). Although some people call this as the "new, emerging pedagogy" (Ontario, 2014), many people say that using outdated methods based primarily on information transmission using computer marked exams, assignments, etc. are not pedagogically sound. Most importantly, the main problem is the lack of one-to-one learning and collaboration.

MOOC providers are now working on the problems associated with collaboration and we briefly discuss it in "Learning by Teaching" section, but shortly, the second era of MOOCs, which is called MOOC 2.0, might be a solution to this concern.

What makes people believe that a new pedagogical perspective is needed for MOOCs? Clearly, the world has changed a lot with the Internet and technological innovations. We are now living in a faster world and the demands of people have increased greatly. Information is all around us, but knowledge and wisdom is needed to use it. Therefore, people will never stop learning to accomplish their intentions, but they do not have enough time to do so since they are busy of working. MOOCs can be a cure for this because the courses do not have limited time spans 
and people can watch the content any time they want. Indeed most of the MOOC participants are highly educated people, which support our argument. According to a research conducted by the University of Pennsylvania, 79.4 percent of the students have a Bachelor's degree or higher and 44 percent have education beyond a Bachelor's degree. Over 40 percent are under the age of $30,56.9$ percent are males and only 13.4 percent are unemployed or retired (Christensen et al., 2014).

Taking these into consideration, seven key elements contributing to the development of the new pedagogy are listed below (Ontario, 2014):

$>$ Blended learning: Closer integration of online and classroom based teaching. Learning, reading, exams and quizzes are done online and class hour is reserved for discussion and interaction with the instructor.

$>$ Collaborative approaches: The professor cannot deliver all the sources, but they are in the role of guiding. With the development of communities through the social media, students can share, discuss and learn from each other. Old style teaching is unnecessary.

$>\quad$ Use of multimedia: Following the Ted talks, iTunesU, MIT's OpenCourseWare, Khan Academy, etc. are now part of a course. There are also interactive materials, animations and graphics for the students to learn more effectively.

$>\quad$ Increased learner control, choice and independence: There are many choices for the students on the Internet even for free. They can choose any subject they want to study, so a strict curriculum chosen by an instructor is meaningless.

$>$ Anywhere, anytime, any size learning: Everyone is using mobile devices and they are the basis of this concept. They can be integrated to course content, quizzes, communication among the learners, etc. Also the "just in time, just for me learning" approach is fulfilling the immediate needs of a learner.

$>$ New forms of assessment: Learning analytics, peer assessments are used throughout the course and they give important feedback before the final assessment.

$>$ Self-directed, non-formal online learning: MOOCs provide a motivation for selfdirected and non-formal learning.

With these in mind, roles of the instructors are changing and assessments need to be considered differently. These concerns come to a single point, collaboration, which we discuss later in the text.

\section{Certification vs. University Credit}

The third common concern about MOOCs is the certification. Previously, in 2012, people were questioning why the students who passes a course in Coursera or edX and receive a certificate couldn't exchange it with a university credit. There was big controversy about it (Daniel, 2012). However, today, some universities' perspective has changed. It is up to the institutions to accept converting a verified certificate to credit. In 2013 American Council of Education (ACE) announced that they would recommend colleges to grant credit for some MOOCs (Korn, 2013) and approved five courses of Coursera for credit (Masterson, 2013). San José State University (SJSU) on the other hand run a pilot with Udacity to offer three math MOOCS for credit with a fee of $\$ 150$ in 2013 (Harris, 2013a). The idea of replacing the classwork experience 
unfortunately failed as the pass rate of online students was lower than the ones who took the course on campus. As a result, SJSU decided to pause these courses. There were many factors resulting this failure; firstly, the courses were put together in a rush, they were announced fortnight before classes started, as a result of the student monitoring was unsuccessful because the faculty was engaged in preparing the courses in parallel to running the course (Rivard, 2013). SJSU then reviewed the process and started the courses in Spring 2014 semester (Harris, 2013b). In Table 1, official result of the pilot project is given from (Firmin et al., 2013, S.1.)

Table 1. First results of the pilot project in SJSU

(Firmin et al., 2013, table S.1)

\begin{tabular}{ccc}
\hline Course & & \% Pass \\
\hline \multirow{2}{*}{ Math 6L } & Matriculated & 29.8 \\
& Non - Matriculated & 17.6 \\
Math 8 & Matriculated & 50.0 \\
& Non - Matriculated & 11.9 \\
\multirow{2}{*}{ Stat 95 } & Matriculated & 54.3 \\
& Non - Matriculated & 48.7 \\
\hline
\end{tabular}

In Figure 3, we see the effect of solving the problem sets to passing the class.

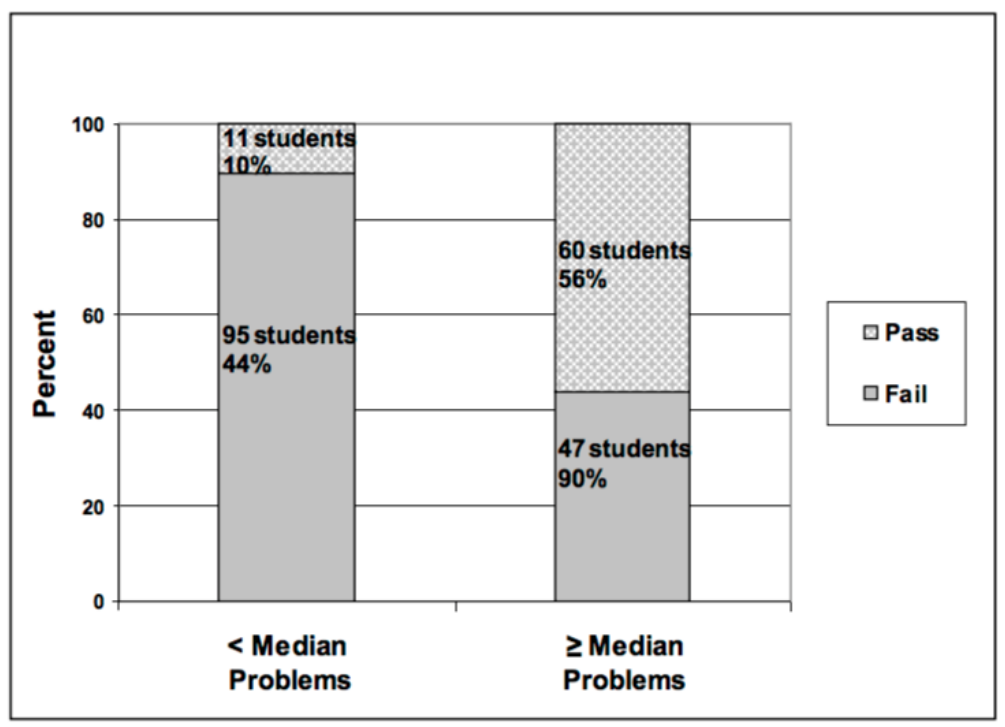

Figure 3. Effect of submitted problem sets to passing (Firmin et al., 2013, figure S.1.)

In the meantime, SJSU announced to continue using edX platform as supplement to their classwork (Rivard, 2013). This is an example of a blended learning where the students watch edX video lectures before coming to class (Carr, 2013), therefore the time spent to lectures decreased and interaction, discussion time with the students increased together with the course pass rates. This also helps ease the capacity problems (Fitzgerald, 2013). Additionally, Coursera made a partnership with 10 US State Universities (Kolowich, 2013) to use blended teaching model and give credit to students. 
Georgia Tech University on the other hand is giving "massive online master's degree in computer science" in collaboration with Udacity and AT\&T for $134 \$$ per credit hour and $301 \$$ per credit term (OMSCS, 2014).

Apart from these, some universities require the completion of an assessment given by the University (Sandeen, 2013) to get a credit out of MOOCs. And finally, CLEP (Colloge Level Examination Program in US) and DSST (a program to receive college credits outside the traditional classroom in US) programs allow the students to take credit-by exam tests. Students can convert their knowledge gained in MOOCs to credit in US through these exams (ADO, 2013). As the examples show, there are lots of opportunities to get credit out of a MOOC completion certificate but it is mostly up to the institutions. In the near future, the opportunities will increase undoubtedly.

\section{THE SOCIAL ERA OF MOOCs - BLENDED LEARNING AND TAs}

Following the MOOCs' initial popularity, the act has progressed considerably. Now the most popular concepts in the online education world are collaboration and blended learning. We call this new era as "social MOOCs" which is also called MOOCs 2.0 for some people.

Initially MOOCs were endeavoring to pass knowledge to students in the form of short videos, reading materials, assignments and exams. The only interactions between the users were in the form of forums, which is a primitive style of collaboration for today.

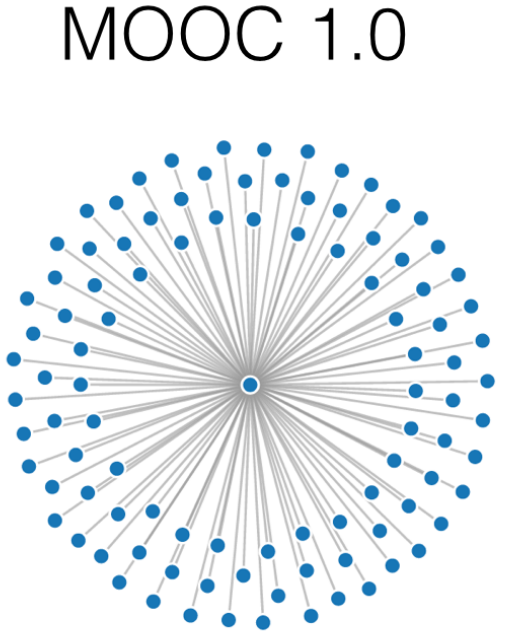

MOOCs scale on first dimension: content delivery
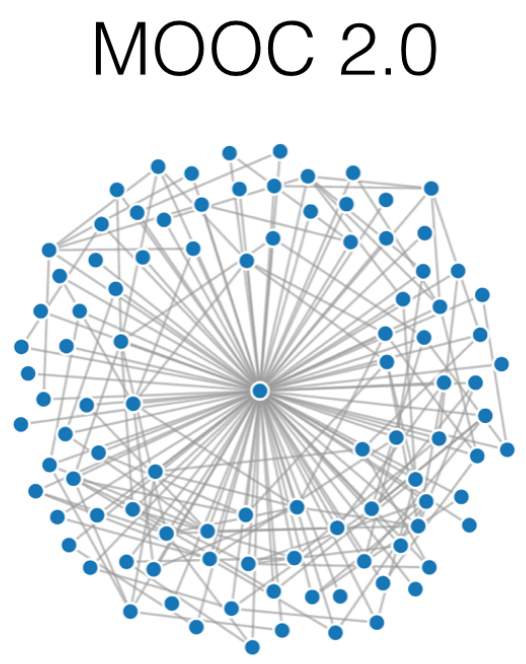

MOOCs scale on second dimension: 1-on-1, face-to-face learning

Figure 4. MOOC 1.0 vs. MOOC 2.0 (Salathe, 2014)

Figure 4 visualizes the main difference between the old style MOOC 1.0 and the new era, MOOC 2.0. As the figure displays, in MOOC 2.0, there are more interactions among the participants. These can be in the form of peer-assessments (Suen, 2014), face-to-face learning, etc. Today new possible interactions are being researched.

In Coursera, some of the courses use a tutoring service given by the students who complete the previous offerings of the course successfully. These students are selected from the ones who mostly achieved 100 percent success in the assignments and were helpful to others in 
discussion forums. Some of these tutors are helping for free but some requests a fee. They give face-to-face help to the students of the course online. In this context, a distinct idea called Teeays has been developed (Salathe, 2014). Anyone can join the website and become a TA for MOOCs in various platforms. A TA gives just-in-time help to the students in the form of video chat over Skype. Each TA has a rating determined by the students. As the rating increases, TAs begin to earn money. In turn, the students can choose a TA for a specific course using their ratings. Higher ranked TAs' tutoring is more expensive which is also an indication of a TAs success.

The second component of MOOC 2.0 is the use of blended learning. It integrates MOOCs and the traditional classrooms, in other words, the online materials and face-to-face learning. There were flipped classroom traditionally, a form of blended learning, where the students study the contents of the lecture through online videos created by their instructor. In the class they used to have more time to explore the contents of the video lectures more deeply and discuss with their instructors (Bruff et al., 2013). Today, this is integrated to MOOOC platforms where the students are asked to participate a MOOC hosted by any institution. The real class supports the online course, which is similar to the traditional flipped class approach. So some instructors today use the existing MOOCs as the online component of their courses without having to prepare the content themselves. With this approach, more time is given to discussions and communication inside the class like the flipped classrooms. This not only improves the self-study ability, which is gained through MOOCs, of the students, but also improves teamwork through the classroom discussions. At MIT, Anant Agarwal says, two out of every three undergrads use edX as part of their on campus courses (Lapowsky, 2014). Through blended learning, students also have the chance to discuss the lecture and content with thousands of other students who take the course online. They are not limited to the students and instructors in their traditional classrooms.

A case study (Bruff et al., 2013) states that the students like this approach's flexibility, customization, and accessibility, which encourage structured self-paced learning. Although the success of the approach is emphasized in the paper, more experiments should be held before coming up with a strong conclusion. In a survey with $\mathbf{3 5 0}$ four-year college presidents, 81 percent expect the blended courses to have a positive effect on higher education (HM, 2014).

\section{DISCUSSION AND FUTURE PREDICTIONS}

We have witnessed the evolution of MOOCs in two years but MOOCs are not new, it is an enhanced learning, which actually has decades of history. The education and the Internet evolved independent from each other and MOOCs have merged them. These two concepts are vital in our lives and the humanity will hopefully benefit from this. In this section we give some future projections about education in the spirit of MOOCs.

Firstly, we see that MOOCs do not have an impact in everyone's life today, only the interested people from the academia are aware of this. I believe this act will spread everywhere include high schools, middle school and even the elementary schools. Additionally, it will be a part of all the students' education program beginning from the universities. The first steps of this effect can be realized in Erasmus Program, which is a very popular European Union student exchange program. Adam Tyson, head of Erasmus unit for higher education at the European Commission, announced that they want to offer any course supported by Erasmus are made open source (Glader, 2012). This means hundreds of MOOCs offered by the European Universities. 
The second challenge may be related to personalization. The courses may be individualized when the importance of a traditional degree becomes irrelevant and learning becomes a continuous, on-the-job process (Horn and Christensen, 2013). This will lead us to a point where people will be free to study on the topics of interest or need and will not have a degree concern.

Thirdly, open source MOOC platforms will be available and people will be able to upload mini lectures to share knowledge. Open edX is such an example where people are able to contribute to edX platform. Academic Room [6] is another such platform, basically different from Open edX, allows the individual academics, researchers, and students to create highly specialized portals for their subfields. This is a kind of open community that supports the new era of MOOCs.

And lastly, we can add three more potential changes in education described partly in (Daniel, 2012); reduction in the University costs, education in undeveloped countries and improvement in the quality of teaching. The University education is US is unaffordable for most people where the annual college fees are around $\$ 40.000$ (UT, 2014). The free nature of MOOCs will help reduce these costs to only a manageable limit because research needs money but the governments and companies cannot compensate all the expenses including the labor. Secondly, the education level in undeveloped countries can be increased with the help of MOOCs. This will take a longer time since the language difference and access to the contents may be a problem to be solved. Blended education type programs where an instructor assists people during the education process can be a cure. Lastly the quality of teaching will be increased because all the contents will be open to everyone and the students will not just because of its name but because of its education and teaching quality since an undergraduate student may not need a university with profound research opportunities and experience, they need the optimum education for their business life in today's world. Research related requirements are mostly for graduate schools.

Hopefully, in the near future, these initiatives will open a way to question the importance of knowledge. It is all around us and we can easily gain access to it. Therefore, we can question whether the knowledge is the true purpose of life. We will be able to reach any knowledge anytime and anywhere but this will not make us gratified from life. A search for wisdom might be the new motivation thereafter.

\section{CONCLUSION}

In this paper I endeavor to summarize and discuss the current state of the new era of education, the MOOCs. Although it is not a new concept, not all the people, even in academic world, are not benefiting from it fully. In addition to this, there are still various problems that need to be solved. The common ones include the completion rates, pedagogy and certification. I believe that these problems cannot be considered similar to the traditional educational approaches. The online nature of the MOOC platform should be kept in mind when making a decision.

TAs and blended learning are the newer concepts in the world of education and they are to change numerous practices. The new era, MOOCs 2.0 not only helps people learn the topics more easily by discussing with thousands of others, watching the online lectures of top instructors all around the world and having the freedom to study anytime, anywhere, but it also forces the instructors to improve themselves every day. Today, the information is everywhere and the students are aware of this. Therefore, the instructors need to prepare the course curriculum using the latest information so they must follow the literature closely. Lastly 
the future of MOOCs is what most people are questioning. I believe that the current wind of MOOCs is the indication of its future. It will certainly change how we perceive the education.

A famous quote says, "College is a place where a professor's lecture notes go straight to the students' lecture notes, without passing the brains of either." (Lillie, 2012). However, online education or MOOCs are now changing this practice. Education is more interactive and cooperative now. There is no point in keeping notes of the professor. The knowledge is as close as a smart electronic device to anyone. Students will choose which information to conceive among many. Today we don't need to memorize, but use the available content and organize. This new era of MOOCs will change our lives and relations, hopefully in good manner.

\section{BIODATA and CONTACT ADDRESSES of AUTHOR(S)}

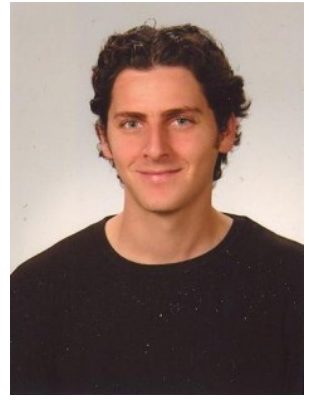

Arda SOYLEV is working as a research assistant in Computer Engineering Department of Necmettin Erbakan University. He received his M.Sc and B.Sc degrees in Computer Engineering from TOBB ETU University and FMV Isik University in 2013 and 2007 respectively. Currently, he is a Ph.D. candidate at the Department of Computer Engineering in Bilkent University under the supervision of Dr. Can Alkan. His main research areas are bioinformatics, computational genomics and algorithms. He is also interested in education and e-learning.

Arda SOYLEV

Department of Computer Engineering

Faculty of Engineering and Architecture

Necmettin Erbakan University, 42090, Konya, Turkey

Phone: +90 3322362144 (4033),

E-mail: asoylev@konya.edu.tr

\section{REFERENCES}

Affordable Degrees Online (ADO), 2013. "MOOCs that offer credit by exam". Retrieved 29 April 2016 from http://www.affordabledegreesonline.org/college-for-free/moocsthat-offer-credit-by-exam/

Bates, T. (2012). What's right and what's wrong about Coursera-style MOOCs. Retrieved 19 April 2016 from http://www.tonybates.ca/2012/08/05/whats-right-and-whatswrong-about-coursera-style-moocs/

Bruff, D. O., Fisher, D. H., McEwen, K. E., \& Smith, B. E. (2013). Wrapping a MO0C: Student perceptions of an experiment in blended learning. Journal of Online Learning and Teaching,9(2), 187.

Christensen, G., Steinmetz, A., Alcorn, B., Bennett, A., Woods, D., \& Emanuel, E. J. (2013). The MOOC phenomenon: who takes massive open online courses and why?. Retrieved 19 April 2016 from https://papers.ssrn.com/sol3/papers. cfm?abstract_id=2350964

Colvin, K. F., Champaign, J., Liu, A., Zhou, Q., Fredericks, C., \& Pritchard, D. E. (2014). Learning in an introductory physics MOOC: All cohorts learn equally, including an oncampus class. The International Review of Research in Open and Distributed Learning, 15(4). 
Daniel, J. (2012). Making sense of MOOCs: Musings in a maze of myth, paradox and possibility. Journal of Interactive Media in Education, 2012(3).

Carr, D. F. (2013). "San Jose State U. Suspends Udacity MOOC Project", Information Week (18 June). Retrieved 29 April 2016 from http://www.informationweek.com/ software/san-jose-state-u--suspends-udacity-mooc-project/d/d-id/1110807

Firmin, R., Schiorring, E., Whitmer, J., Willett, T., \& Sujitparapitaya, S. (2013). "Preliminary summary SJSU+ Augmented Online Learning Environment pilot project".

Fitzgerald, M. (2013.) "California Expands Use Of MOOCs", Information Week (11 April). Retrieved 29 April 2016 from http://www.informationweek.com/software/ california-expands-use-of-moocs/d/d-id/1109492?

Georgia Tech College of Computing (OMSCS), (2014). Retrieved 29 April 2016 from http://www.omscs.gatech.edu

P. (2012). "EXCLUSIVE: EU's Erasmus Prepares College Rankings, MOOC Class Rivals to Udacity, edX, Coursera", Wired Academic. Retrieved 29 April 2016 from http://www.wiredacademic.com/2012/05/exclusive-europes-erasmus-prepares-tolaunch-college-rankings-mooc-classes

Glance, D. G., Forsey, M., \& Riley, M. (2013). The pedagogical foundations of massive open online courses. First Monday, 18(5).

Guo, P. J., Kim, J., \& Rubin, R. (2014, March). How video production affects student engagement: An empirical study of mooc videos. In Proceedings of the first ACM conference on Learning@ scale conference (pp. 41-50). ACM.

Harvard Magazine (HM), 2014. "Online Evolution". Retrieved 29 April 2016 from http://harvardmagazine.com/2014/09/online-evolution

Harris, P. (2013a). SJSU and Udacity Partnership. Retrieved 29 April 2016 from http:// blogs.sjsu.edu/today/2013/sjsu-and-udacity-partnership/.

Harris, P. (2013b). "SJSU/Udacity: Spring 2014 Update", SJSU Today. Retrieved 29 April 2016 from http://blogs.sjsu.edu/today/2013/sjsuudacity-update-spring-2014/

Hill, P. (2013). Emerging student patterns in MOOCs: A (revised) graphical view. e-Literate. Retrieved 29 April 2016 from http://mfeldstein.com/emerging-student-patterns-inmoocs-a-revised-graphical-view/

Horn, M., \& Christensen, C. (2013). Beyond the buzz, where are MOOCs really going. Opinion, Wired.

Koller, D., Ng, A., Do, C., \& Chen, Z. (2013). Retention and intention in massive open online courses: In depth. Educause Review, 48(3), 62-63.

Kolowich, S. (2013). In deals with 10 public universities, Coursera bids for role in credit courses. The Chronicle of Higher Education, 30.

Korn, M. (2013). Big MOOC coursera moves closer to academic acceptance. Wall Street Journal, February, 7. 
Lapowsky, I. (2014). Why Free Online Classes Are Still the Future of Education. Wired. Retrieved 29 April 2016 from http://www.wired.com/2014/09/free-online-classesstill-future-education/

Lillie, B. (2012). "Massive online education: Daphne Koller at TEDGlobal 2012", TedBlog (26 June). Retrieved 29 April 2016 from http://blog.ted.com/2012/06/26/massiveonline-education-daphne-koller-at-tedglobal2012/

Maas, A., Heather, C., Do, C. T., Brandman, R., Koller, D., \& Ng, A. (2014). Offering verified credentials in massive open online courses: MOOCs and technology to advance learning and learning research (Ubiquity symposium). Ubiquity, 2014(May), 2.

Markoff, J. (2011). Virtual and artificial, but 58,000 want course. The New York Times, 15.

Masterson, K. (2013). Giving MOOCs some credit. ACE. Retrieved 29 April 2016 http://www.acenet.edu/the-presidency/columns-and-features/Pages/GivingMOOCs-Some-Credit.aspx,

Ontario Online Learning Portal, 2014. "A New Pedagogy is Emerging... and Online Learning is a Key Contributing Factor". Retrieved 29 April 2016 from http://contactnorth.ca/trends-directions/evolving-pedagogy-0/new-pedagogyemergingand-online-learning-key-contributing

Pappano, L. (2012). The Year of the MOOC. The New York Times, 2(12), 2012.

Parr, C. (2013). Mooc creators criticise courses' lack of creativity. Times Higher Education, 17(03), 2013.

Rivard, R. (2013). Udacity project on «pause». Inside Higher Ed, 18.

Salathe, M. (2014). MOOCs 2.0: Scaling One-on-One Learning. Retrieved 15 April 2016 from https:// www.wired.com/insights/2014/09/moocs-2-0/

Sandeen, C. (2013). Integrating MOOCs into traditional higher education: The emerging "MOOC 3.0" era. Change: The Magazine of Higher Learning, 45(6), 34-39.

Suen, H. K. (2014). Peer assessment for massive open online courses (MOOCs). The International Review of Research in Open and Distributed Learning, 15(3).

Top Universities (UT), 2014 "Tuition Fees at the World's Top Universities". Retrieved 29 April 2016 from http://www.topuniversities.com/student-info/student-finance/tuitionfees-world's-top-universities 